\title{
Assessment of the possibility of implementing the GLOBAL G.A.P. standard in selected bean- producing farms in western Kyrgyzstan
}

\author{
Marcin Niemiec $^{1 *}$ and Monika Komorowska ${ }^{2}$ \\ ${ }^{1}$ Department of Agricultural and Environmental Chemistry, University of Agriculture in Krakow, . \\ Mickiewicza Ave. 21, 31-120 Krakow, Poland \\ ${ }^{2}$ Department of Vegetable and Medicinal Plants, University of Agriculture in Krakow 29 Listopada Ave. \\ 54, 31-425 Krakow, Poland
}

\begin{abstract}
The objective of this study was to assess the potential of implementing GLOBAL. G.A.P. in bean-producing farms in the region of Talas in northern Kyrgyzstan. The assessment concerned the analysis of non-conformities with the GLOBAL G.A.P. standard in farms that had implemented the standard but had not been certified. The detailed objective was to identify critical areas in implementing said standard. To achieve the objective established, research was conducted in 2018. The research covered 112 farms that produce beans (local variety called 'Łopatka'). Internal audits were carried out in the examined farms, in accordance with the checklist of the GLOBAL G.A.P. standard version 5.1. The results of the conducted research indicate that at the current level of agricultural development and awareness of farmers from Kyrgyzstan, implementation of the GLOBAL G.A.P. standard is going to be very difficult. Problems apply both to infrastructure and to producers' mentality. Problems with infrastructure concern primarily the places to store plant protection products as well as mineral and organic fertilizers. Moreover, the identified non-conformities concerned adequate infrastructure serving for segregation and management of waste (both production waste and municipal waste). With respect to hygiene, problems concern both lack of sanitary infrastructure, as well as producers' mentality associated with the need for maintaining hygiene. In most cases, the issue of the possibility of improving the condition of the environment within the farm's premises is omitted. With respect to production technology, using organic and mineral fertilizers is problematic. In no case was water, soil or products analyzed, which is obligatory in the standard being discussed. A considerable problem in the area of the study is lack of support from government entities or companies dealing with efficient implementation of the standard. Effective development of the standard also depends on educating at the level of producers, inspectorate bodies, as well as on introducing quality management courses at individual education levels to the curriculum.
\end{abstract}

* Corresponding author: marcin1niemiec@gmail.com 


\section{Introduction}

The Republic of Kyrgyzstan is a country with a substantial, unused potential of environmental conditions. Kyrgyz economy is among the least developed in Central Asia countries, despite the fact that it is one of the most politically stable countries in that region. An insufficient level of investment translates into shortages of infrastructure in agricultural and industrial production, and also with respect to obtaining energy. Economic development of this country is very important for maintaining democracy in that part of the world, as well as for the development of export from European Union regions. In 2017, German export to Kyrgyzstan was approximately 62 million euros and that was $28 \%$ more compared to 2016. The EU exports mainly machinery, cars and car parts, pharmaceutical products, chemical products and electrical engineering products. The Republic of Kyrgyzstan is a country with a considerable potential in agricultural production, particularly legumes, nuts, fruit and vegetables. Beneficial climatic and soil conditions make it possible to produce good quality beans, chickpea, soybean, apricot, grapes, mulberry and other fruit with high sugar content. Agriculture is an important economic activity. This branch makes $18.5 \%$ GDP. Owing to the considerable fragmentation of farms, $85 \%$ of agricultural production currently comes from small private farms. Due to the growing level of import from neighboring countries (Uzbekistan, Kazakhstan), there has been a steady increase in the area of fallows in recent years. The only factor of the possibility of developing agricultural production is selling products on foreign markets. Next to insufficient infrastructure associated with production, lack of access for farmers to primary production certification systems is one of the main limitations to agricultural development in the context of production for foreign markets [1]. Currently, there is a growing interest of the Republic of Kyrgyzstan in the issues of initiating certification of compliance with the GLOBAL G.A.P. standard. However, this certification depends on effective implementation of the standard, which comprises of factors associated with product safety, environmental protection and social aspects. Effective implementation of the standard requires developing a proper production technology, creating appropriate infrastructure associated with storing and using pesticides and fertilizers, and infrastructure for harvests and storing products. The present-day foodstuff market, particularly in developed countries, is shaped by consumer needs with respect to certification of quality management systems in food production [2, 3]. Optimization of production and logistic processes was etremely important as it aimed to reduce energy consumption and increase work productivity $[4,5]$.

The objective of this study was to assess the potential of implementing GLOBAL. G.A.P. in bean-producing farms in the region of Talas in western Kyrgyzstan. The assessment concerned the analysis of non-conformities with the GLOBAL G.A.P. standard in farms that had implemented the standard but had not been certified. The detailed objective was to identify critical areas in implementing said standard.

\section{Study material and methods}

To achieve the objective established, research was conducted in 2018. The research covered 112 farms that produce beans (local variety called 'Łopatka'). Farms that produce beans intended for export were selected for the study. Until now, the entire production has been sold mainly to Turkey and, in smaller quantities, to other Middle East countries. Despite the existing demand for the product in question in EU countries, the factor that prevents its 
export is the lack of a certificate confirming production of beans in accordance with the GLOBAL G.A.P. standard. The study material was selected by nonprobability sampling method. Commercial farms were used in the study; those farms use the latest available technologies and means of production. While the study was being conducted, the standard was introduced. However, it was not subject to certification. Internal audits were carried out in the examined farms, in accordance with the checklist of the GLOBAL G.A.P. standard version 5.1. Constituents of the standard taken into account in this study concerned the following areas: management of the production site, keeping records, hygiene and health, safety and care for workers, management of wastes and pollutants, environmental protection, protecting food against intentional harmful acts, traceability and segregation. All the studied farms additionally produced other plants, and 86 of them additionally ran animal production (rearing of cattle, sheep, goats and horses) (Fig. 1 and 2). All the studied farms were family-owned.

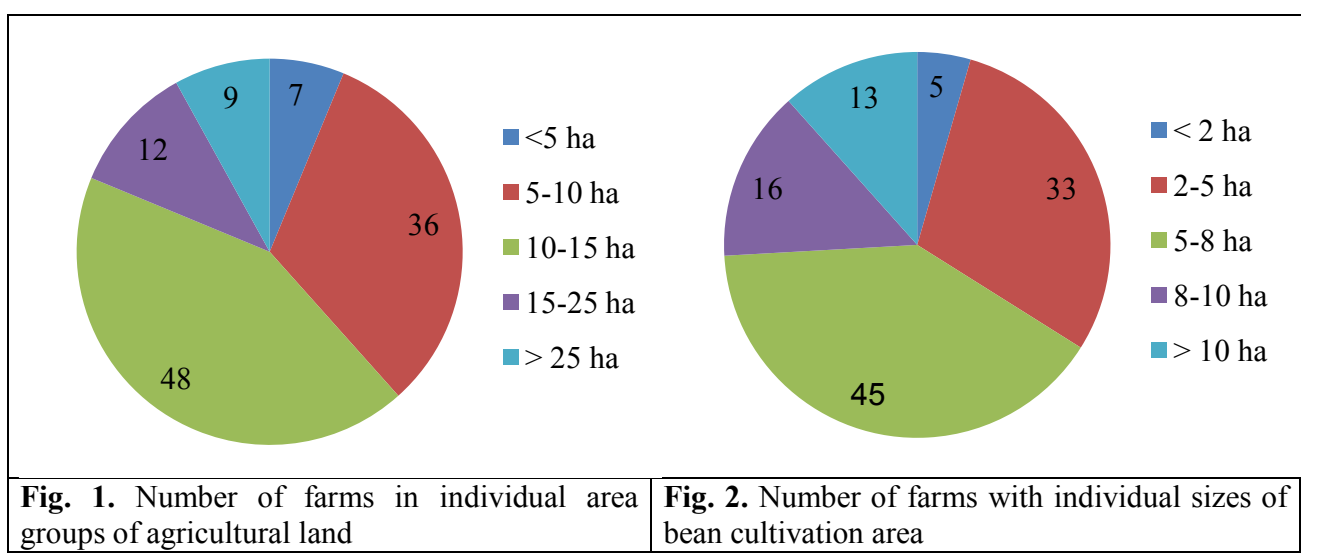

\section{Results and discussion}

Globalization of the food market leads to the need to ensure safety in the entire supply chain. In the global economy, food is transported at long distances, and supply chains are getting longer. Food is subjected to a growing number of processing processes and it is stored longer and longer. For that reason, it can be contaminated unintentionally or intentionally at subsequent stages. This may pose a risk to the end consumer. Therefore, food safety is strategic in food production. Ensuring food safety is possible thanks to formalized quality management systems which have been being implemented for many years in food processing and in the logistics chain. The most important of them, the HACCP system (which is obligatory in food processing), is used to prevent threats to food safety. This obligation is not applicable in primary production. That is why it is so important to promote private quality management systems, in order to ensure a quality system in primary production. Development and implementation of an effective quality management system is difficult and costly. That is why it is impossible to achieve by many small farms, which has been pointed out by many researchers of this problem $[6,7]$. 
Table 1. Number of non-conformities for individual control points

\begin{tabular}{|c|c|c|c|c|c|}
\hline 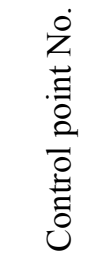 & 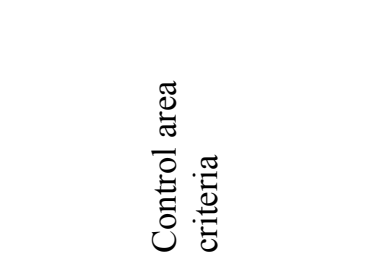 & 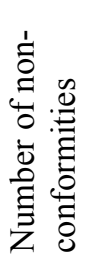 & 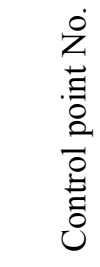 & 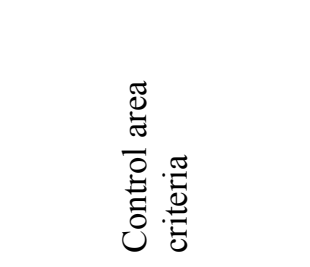 & 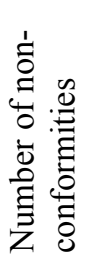 \\
\hline AF. 1 & $\begin{array}{l}\text { History and management } \\
\text { of the production site }\end{array}$ & 102 & CB. 4 & Use of fertilizers & 182 \\
\hline AF. 3 & $\begin{array}{l}\text { Health, safety and care } \\
\text { for workers }\end{array}$ & 366 & CB. 5 & $\begin{array}{l}\text { Irrigation/ } \\
\text { fertigation }\end{array}$ & 100 \\
\hline AF. 5 & $\begin{array}{l}\text { Management of waste } \\
\text { and pollutants, recycling } \\
\text { and reuse }\end{array}$ & 284 & CB. 6 & $\begin{array}{l}\text { Integrated plant } \\
\text { protection }\end{array}$ & 96 \\
\hline AF. 6 & $\begin{array}{l}\text { Environment and } \\
\text { protection }\end{array}$ & 315 & CB. 7 & $\begin{array}{l}\text { Plant protection } \\
\text { products }\end{array}$ & 188 \\
\hline AF. 9 & $\begin{array}{l}\text { Protection against } \\
\text { intentional harmful acts }\end{array}$ & 61 & CB. 8 & Equipment & 106 \\
\hline AF. 12 & $\begin{array}{l}\text { Traceability and } \\
\text { segregation }\end{array}$ & 88 & & & \\
\hline CB.1 & Traceability & 88 & FV. 1 & $\begin{array}{l}\text { Management of the } \\
\text { production site }\end{array}$ & 140 \\
\hline CB. 2 & Propagation material & 0 & FV. 4 & $\begin{array}{l}\text { Actions before } \\
\text { harvest }\end{array}$ & 22 \\
\hline CB. 3 & Soil management & 97 & FV. 5 & $\begin{array}{l}\text { Dealing with the } \\
\text { product after harvest }\end{array}$ & 76 \\
\hline
\end{tabular}

Effective implementation of the GLOBAL G.A.P. standard requires a number of actions connected with perfecting organizational, infrastructural and technological activities [7]. Recently, there has been a considerable increase in the interest in this standard in the Republic of Kyrgyzstan. This results from the needs of foreign customers. The observed trend is caused, above all, by the requirements of fruit, vegetable and legume markets. One of the more important problems associated with implementation of certified quality systems at the farm level is low producer awareness of the principles of the standard, which has been highlighted by experts in this area [8,9]. Verification of the effectiveness of introduced standard is carried out based on audit for compliance with the GLOBAL G.A.P. standard. The audit is carried out based on a checklist which comprises of groups of primary and secondary requirements and recommendations. For the audit result to be positive, all primary requirements and at least $95 \%$ secondary requirements must be met. The checklist of the standard comprises of a base module for farms (All Farm AF.), a module for crops (Crop Base CB.), and a module for specific groups of plants. In the case of the studied farms, inspections for compliance with the fruit and vegetable module (Fruits and Vegetable FV.) were conducted. The number of non-conformities in respective areas of control is presented in Table 1. The results of the conducted study indicate that the lowest number of non-conformities was associated with pre-harvest activities. Non-conformities concerned mainly the lack of risk analysis for natural fertilizers used before harvest, during 
plant vegetation. In all cases harvest was done mechanically. Risk analyses, procedures and instructions were prepared in most of the studied farms. However, a dissection of their contents revealed irregularities associated with not taking into account some aspects occurring in farms, in a specific production and economic reality. Those non-conformities especially applied to points AF 1., AF 3., AF6., AF 12., FV 1. In almost all farms there were non-conformities associated with records on the issue of agricultural engineering activities such as: irrigation, using pesticides, using mineral and organic fertilizers, density of sowing, as well as monitoring of crops within the integrated plant protection (CB. 4, CB. 5, CB. 6). Records describing the history and management of the production site were incorrectly kept in all farms (AF. 1). Generally, the actual effect of management in the past on the risk associated with product safety was not taken into account. There were nonconformities in 56 farms. They resulted from the lack of archiving of sowing density. In 32 and 3 cases, non-conformities applied to the lack of proper crop rotation (CB. 3). The largest number of non-conformities was recorded in the area of health, safety and care for workers (AF 3.). In all the studied farms there were as many as 366 non-conformities in this area. The biggest problems concerning health, safety and care for workers were associated with marking potential threats on farm premises using warning signs. Non-conformities in this area were recorded in 92 farms. There were 72 cases of lack of visible procedures in case of an accident. In accordance with the GLOBAL G.A.P. standard, these procedures must be placed in a visible location, no farther than $10 \mathrm{~m}$ from the warehouse for plant protection products. In 84 farms there were non-conformities associated with the lack of worker trainings on the basics of hygiene and safety regulations. In 16 cases there were no workplace first aid kits. As a result of the conducted internal study, non-conformities associated with waste management were recorded in 102 farms (AF. 5). Non-conformities were associated with the lack of plan for waste management and with failure to dispose of production waste on an ongoing basis. One of the most important aspects of the GLOBAL G.A.P. system is designing a food production system which impacts the environment in a minimum way. This applies particularly to an effective use of water, soil and energy resources. Moreover, within the framework of management compliant with principles of the standard being described, active measures should be implemented to protect biodiversity of agrocenoses and adjoining areas $[10,11]$. Within respect to the environment and its protection (AF. 6), there were as many as 315 non-conformities. The largest number of non-conformities in this area concerned improper developement of a nature protection plan. Most farms did not consider implementing actions leading to an improvement of the condition of the environment, which would benefit local community as well as local flora and fauna. In 88 farms, conditions of storing liquid fuels were inadequate. In 94 farms, the problem was to keep order in the farm. In 88 farms there were non-conformities associated with traceability (AF. 12 and CB. 1). There were procedures for traceability developed in all the farms. However, the problem was to conduct a test for the effectiveness of the traceability system. In most cases the test was conducted improperly. Moreover, in 32 farms warehouses were used collectively by different entities, without product segregation. In those cases, products got mixed already at the storing stage. An effective traceability system is one of the most important aspects of all quality systems in primary production as it allows you to verify the supplier of agricultural products even after their processing [12, 13]. There were errors at the level of system documentation in all cases. The results of the conducted study unambiguously indicate that insufficient knowledge of the people responsible for implementing the standard as well as a misconception about the role of traceability in ensuring food safety at all stages of the supply chain were the source of errors. Sing et al. [14] highlight that an effective traceability system in the supply chain is one of the pillars of a food safety system. Perramon et al. [15] stated that developing an effective traceability system at national level depends on the support at state level. 
A part of the crop production technology that influences the quality and quantity of yield and also the expenditure incurred on protection is the use of propagation material of adequate quality. The system being described forces the producers to use sowing material with quality allowed by local laws. Due to the lack of a systemic approach to the issue of using sowing material in the Republic of Kyrgyzstan, this point is problematic. Therefore, no non-conformities in this area were recorded in the studied farms (CB. 2). All the producers used seeds from their own harvest or purchased, without verifying the quality of sowing material. It is not a non-conformity from the point of view of the standard. However, it is problematic in terms of phytosanitary safety and effectiveness of using means of production. Proper management of soil resources is the basic component of rational agriculture. Planning an adequate set of crops, rational fertilization (in accordance with plant demands), as well as plant protection combining elements of mechanical, chemical and biological protection, is the foundation of modern agricultural systems [11]. The results of the conducted study indicate that all the farms use techniques that improve or help preserve the soil structure, and counteract the destruction of its structure. In the part of the checklist concerning fertilization (CB. 4), there were 182 non-conformities (Tab. 1). In all cases there was a non-conformity associated with the lack of research into soil abundance. This problem results from the lack of access to services within the scope of soil research. Based on a survey carried out among farmers, it was established that most of them did not see any potential benefits of conducting such research on nutrient content. Inefficient fertilization, particularly with phosphorus and potassium, is the commonly mentioned cause of soil degradation in developing countries [16]. In the studied farms, farmer's financial possibilities are the most common factor shaping the level of fertilization. It is incompatible with the principles of the GLOBAL G.A.P. standard. There were nonconformities associated with fertilization techniques in 45 cases. Those farms used natural fertilizers in a top dressing manner, without taking this fact into account in the analysis of risk associated with using natural fertilizers, according to $\mathrm{CB}$. 4. In the group of studied farms, there were 72 cases of non-conformities associated with storing natural fertilizers. Manure was stored in a way which did not secure against leakage of nutrients into the environment. None of the farms stored mineral fertilizers. Organic fertilizers are an important element of rational management of plant nutrients. They affect physical, chemical and physicochemical properties of soil and supply macro- and microelements. When planning fertilization, you must always take into account the applied organic fertilizers so as not to cause excessive concentration of biogens in the environment [17]. Of the studied farms, 62 used irrigation. In all cases there were non-conformities concerning testing of the water used for irrigation and records of the amount of water used for irrigation (CB. 5). The issue of water consumption is very important in the standard being discussed, and in its subsequent versions more and more attention is focused on the issues of water management. Non-conformities in the area of irrigation and fertigation constituted a relatively numerous group. Agriculture is a sector of economy which, on a global scale, consumes the largest amounts of water. About $20 \%$ of crops worldwide are irrigated. In Central Asia countries there has been a growing water deficit in recent years. This is associated with climate changes [17]. That is why it is very important to implement effective irrigation methods, not only from the point of view of implementing the GLOBAL G.A.P. standard, but mainly in the context of ensuring steady development. Water shortages in years to come may significantly limit primary production. Effective management of organic matter and waste is an additional aspect that is playing a greater and greater role in modern production technologies. According to the requirements of the standard, biodegradable waste should be composted to return biogens to primary production. Niemiec et al. [18] and Sikora et al. [19] show possibilities of rationalization of using waste (both of plant and animal origin) as raw material for methanogenesis. In such arrangements, energy 
bound by plants is recovered during photosynthesis and biogens are returned when using digestate mass as an agent improving soil properties. The results of the conducted study point to a considerable number of non-conformities associated with integrated plant protection (CB. 6). Non-conformities in this area concerned the lack of trainings or inadequate competence of people responsible for plant protection at the farm. The region where the study was carried out lacks technological support for agricultural production. Farmers do not have access to competent advisors on integrated plant protection and on using plant protection products. Within the scope of plant protection products, there were 106 non-conformities. The general problem is the lack of invoices for their purchase. Warehouses for plant protection products were organized in 42 farms. However, in 13 cases were they compliant with the requirements of the standard. The biggest problems with storing plant protection products are connected with infrastructure. In old farms, warehouses for plant protection products are usually created by adapting the existing buildings. The most common problems associated with warehouses for plant protection products in the farms participating in the study concerned the lack of ventilation and the lack of a storage reservoir that would stop potential leakage. All the studied farms conduct postharvest processing, storing and packing. As a result of the conducted study, nonconformities associated with management of the production site in accordance with the harvest hygiene risk assessment (FV 1) were determined. A lot of non-conformities concerned the post-harvest activities. They were associated mainly with the risk analysis, harvest hygiene and packaging hygiene, and also with storing the products. The results of the conducted study point to a low potential of the studied farms with respect to implementing quality management systems.

\section{Summary}

The results of the conducted research indicate that at the current level of agricultural development and awareness of farmers from Kyrgyzstan, implementation of the GLOBAL G.A.P. standard is going to be very difficult. Problems concern both infrastructure and producers' awareness. Non-conformities with respect to infrastructure are associated mainly with the places to store plant protection products as well as mineral and organic fertilizers, and also adequate infrastructure serving for segregation and proper management of waste (both production waste and municipal waste). The biggest problem concerning hygiene was the lack of sanitary infrastructure, as well as producers' mentality associated with the need for maintaining hygiene. The conducted study indicates that documentation (risk analyses, procedures and instructions) was inadequate to the magnitude and scope of activities in all farms. The largest number of non-conformities concerned risk analyses. Sources of risk and the potential effect on product quality were often defined incorrectly in the risk analyses. According to the opinion of numerous producers, creating social infrastructure for workers is not economically justified, since in most cases workers are employed seasonally or they are family members. The issue of the possibility of improving the condition of the environment within the farm's premises is very often omitted. With respect to production technology, using organic and mineral fertilizers is problematic. In no case was water, soil or products analyzed, which is obligatory in the standard being discussed. A considerable problem in the area of the study is the lack of support from government entities or lack of companies dealing with efficient implementation of the standard. Effective development of the standard also depends on educating at the level of producers, inspectorate bodies, as well as on introducing quality management courses at individual education levels to the curriculum. 


\section{References}

1. E. Lioubimtseva, Encyclopedia of Food Security and Sustainability 3 (2019).

2. M. Kuboń M. Sporysz S. Kocira, 17th International Multidisciplinary Scientific GeoConference SGEM 2017. Conference Proceedings, 17, 57 (2017).

3. A. Szeląg-Sikora, M. Niemiec, J. Sikora, M. Chowaniak, IX International Scientific Symposium "Farm Machinery and Processes Management in Sustainable Agriculture" Lublin, Poland, (2017).

4. M. Kuboń, A. Krasnodębski, Agr. Econ. 56 (2010).

5. M. Cupiał, A. Szela g-Sikora, M. Niemiec, M. Agric. Agric. Sci. Proc., 7, 64-6, (2015).

6. D. Tran, D. Daisaku, Food Policy, Available online 7 December 2018 In Press, Corrected Proof. (2018).

7. B. Azhar, M. Prideaux, N. Razi, Encyclopedia of Food Security and Sustainability 2 (2019).

8. C. Oya, F. Schaefer, D. Skalidou, World Development 112 (2018).

9. S. Srisopaporn, D. Jourdain, S.R. Perret, G. Shivakoti, Technological Forecasting and Social Change 96 (2015).

10. N. Changkid, Procedia - Social and Behavioral Sciences 91 (2013).

11. Z. Gródek-Szostak, G. Malik, D. Kajrunajtys, A. Szelag-Sikora, J. Sikora, M. Kuboń, M. Niemiec, and J. Kapusta-Duch, Sustain. Switz. 11, (2019).

12. J. Hu, X. Zhang, L. M. Mog, M. Neculita, Food Control 30, 1 (2013).

13. R. Badia-Melis, P. Mishra, L. Ruiz-García, Food Control 57 (2015).

14. B. Perramon, A.D. Bosch-Serra, F. Domingo, J. Boixadera, Eur. J. Agron. 76 (2016).

15. K. Singh, T. Sanderson, D. Field, C. Fidelis, D. Yinil, Geoderma Regional, (17, June, in press, 2019).

16. Z. Gródek-Szostak, A. Szeląg -Sikora, J. Sikora, M. Korenko, Business and Non-profit Organizations Facing Increased Competition and Growing Customers' Demands (Eds. A Ujwary-Gil, A Nalepka), Wyższa Szkoła Biznesu - National-Louis University, Nowy Sacz, 16, 427-439, (2017).J. Ding, B. Huang, X. Jia, J. Bai, S. Boucher, M. Carter, J. Integr., Agri. 14, 11 (2015).

17. Q. Han, C. Li, C. Zhao, Y. Zhang, S. Li, Grazing decreased water use efficiency in Central Asia from 1979 to 2011. Ecol. Model. 388 (24 November 2018).

18. M. Niemiec, M. Komorowska, A. Szeląg-Sikora, J. Sikora, N. Kuzminova, J. Elem. 23(3), 1009-1020, (2018)

19. J. Sikora, M. Niemiec, A. Szelag-Sikora, M. Kubon, E. Olech, and A. Marczuk, Przemysl Chem. 96, 11, 2275-2278, (2017). 